The impact of effective reading strategy instruction on EFL learners

Bozorgian, Mojtaba $\measuredangle$

Applied Linguistics, Brock University, St. Catharines, ON, Canada(mb16qz@brocku.ca)

Aalaam, Mehdi

Islamic Azad University, North Tehran Branch, Iran (mehdiaalaam@gmail.com)

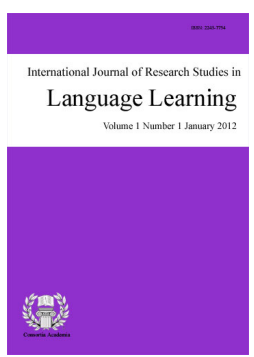

ISSN: 2243-7754 Online ISSN: 2243-7762

OPEN ACCESS

\title{
Abstract
}

This study investigated the relationship between Iranian elementary EFL learners' reading strategy instruction and their performance on different reading comprehension test types. In addition, it studied the differences among these learners' reading strategy preferences based on their personality types. A total of 60 Iranian EFL learners at the elementary level within the range of 15-30 years old were selected from among 100 participants. The participants were then divided into two groups of control $(n=30)$ and experimental $(n=30)$. Subsequently, reading strategies were taught to the experimental group during ten sessions. The findings indicated that reading strategies instruction had a significant impact on reading comprehension of the participants in the experimental group at the end of the treatment. These participants of different personality types did better in posttest of CL-test and multiple-choice test. Additionally, analysis of the results showed that participants tended to use metacognitive reading strategies more than cognitive and support strategies.

Keywords: reading comprehension; reading strategies; EFL 


\section{The impact of effective reading strategy instruction on EFL learners}

\section{Introduction}

In an educational environment, reading is one of the most crucial skills for acquiring knowledge and gathering information for academic accomplishment and beyond (Alfassi, 2004; Wei, 2005). Besides, reading is a basic and complementary skill in language learning because learners can probably learn to read more easily than they can acquire any other skills, and they "can use reading materials as a primary source of comprehensible input as they learn the language" (Chastain, 1998, p.216). In countries like Iran where English is a foreign language and the amount of language input through listening is limited in most learners' everyday lives, reading is a very important source of input. Therefore, reading is an essential skill that can serve as the basis of the development of the other major skills, such as listening, speaking, and writing. Despite this importance, it is the common experience that most learners fail to read adequately in the foreign language.

During the last two decades, a steady shift has happened in teaching and learning EFL/ESL resulting in the emphasis on the learner and their learning process rather than the emphasis on the teachers and their teaching process (Iverson, 2005). This considerable change has caused a substantial attention to understand what proficient and skilled readers do while reading, including identifying the learning strategies they use and how and under which conditions they use the learned strategies (Garner, 1987; Block, 1992; Sheorey \& Mokhtari, 2001).

Positive effect of reading strategies on enhancing reader's comprehension have shown that those who apply these strategies have been found successful readers (Song, 1998; Singhal, 2001). Reading strategies can be helpful in the classroom to assist any learner in learning. Learners can better understand the purpose of reading by giving them tools to assist them with comprehension. Besides, teaching learners how to be active readers and work to comprehend text through active reading strategies before, during, and after the reading process (Gillet, Temple, Crawford, \& Cooney, 1990) is the beginning of teaching learners how to think critically and utilize metacognitive skills. The various studies and projects in the field of reading comprehension imply the necessity of instructing learners on how to use these strategies while reading, but the important point is that not all learners use the same strategies and many individual differences, such as motivation and attitude affect the type, number, and frequency of language learning strategies.

One factor which may take a lot of interest is the effect of personality type of the reader on using reading strategies. The great Swiss physician-psychologist, C.G., Jung introduced the theory of "Personality type" first. Later, Katherine Cook Briggs and her daughter, Isabel Briggs Myers, developed Myers-Briggs Type Indicator (MBTI) in 1942. MBTI has become the most trusted and widely used personality inventory. MBTI describes that different people have different personality traits. These people use different ways to approach a task with their own personality traits. According to the theory behind MBTI, people have individual preferences concerning what they pay attention to, how they make decisions, draw conclusions, and how they approach and respond to different tasks (Sharp, 2004).

While researchers have conducted a good number of studies on reading strategies in the English as a foreign/second language field, very little is known about the issue of the relationship between MBTI and learner's use of reading strategies. Another point is that most of the studies in the field of teaching EFL (TEFL) have dealt with language learning strategies (Barfarazi, 2008). The term "language learning strategies" as a general term can be narrowed down to more specific domains, such as reading strategies.

Identification and classification of reading strategies is the result of the emphasis on reading as a cognitive process which caused the development of a different taxonomy of reading strategies. Grabe (1991) subdivided the process of fluent reading into six component skills including "automatic recognition skills, vocabulary and 
structural knowledge, formal discourse structure knowledge, content/world background knowledge, synthesis and evaluation skills/ strategies, and metacognitive knowledge and skills monitoring" (p. 379). According to Auerbach and Paxton (1997), reading strategies can be divided in three categories of "pre-reading, during-reading, and after-reading strategies" (p. 259). Block (1986) identified two levels for reading strategies, namely as 'general comprehension' and 'local linguistic strategies' (p. 472). Brown (2001) also introduced some reading strategies such as identifying the purpose in reading, using graphemic rules and patterns, decoding, using efficient silent reading techniques for relatively rapid comprehension, skimming the text for main idea, scanning the text for specific information, using semantic mapping or clustering, guessing when you are not certain, analyzing vocabulary, distinguishing between literal and implied meaning as well as capitalizing on discourse markers to process relationships (p. 306). Furthermore, Abbot (2006) specified bottom-up and top-down processing in his classification of reading strategies during his investigation of Arabic and Mandarin EFL learners' reading strategy use. Finally, Mokhtari and Reichard (2002) classified reading strategies into three categories, namely, metacognitive, cognitive, and support strategies (p. 249). Mokhtari and Reichard's (2002) classification of reading strategy was employed in this study to train the Iranian EFL learners to make best choices in reading strategy use.

An increasingly common view in the research literature is that reading is essentially divided into two components: decoding (word recognition) and comprehension (Gough, Ehri, \& Treiman, 1992). It is common to make a distinction between the process of reading and the result of that process as a product, which means what one has understood. Whereas, the process is what is meant by reading proper, the interaction between a reader and the text. During that process, presumably, many things are happening. The process is likely to be dynamic, variable and different for the same reader on the same text at a different time or with a different purpose in reading. According to Alderson (2000), product approaches to reading have been unfashionable in recent years as research efforts concentrated on understanding the reading process. However, a great deal of research into reading earlier this century used essentially product approaches to reading, and much research into the effect of linguistic variables still concentrates on the product of reading (pp. 3-5).

The complexity of reading comprehension presents challenges for assessment, especially as many of the cognitive processes that contribute to reading comprehension are hidden and therefore cannot be directly observed or measured. Hence, relying on only one method to test reading comprehension is not advised. According to Khoshsima and Pourjam (2014), "no single test method can fulfill all the varied purposes for which we might test" (p. 19). These researchers found that the reading comprehension of those students who took cloze tests and open-ended questions differed significantly from those of the students who took traditional way of teaching reading comprehension, namely multiple-choice technique.

\subsection{Reading Comprehension Test Type}

There are some common techniques for reading comprehension as follow:

$>$ According to Alderson (2000), cloze tests are typically constructed by deleting from selected texts every nth word (n usually being a number somewhere between 5 and 12) and simply requiring the test-takers to restore the word that has been deleted.

$>$ Multiple choice questions are common device for testing learners' text comprehension. They allow testers to control the range of possible answers to comprehension questions, and to some extent to control the learners' thought processes when responding (Munby, 1968).

$>$ Multiple matching in which there are two sets of stimuli that the examinees should match against each other. For example, matching headings for paragraphs to their corresponding paragraph or titles of books against extracts form each book (Alderson, 2000, p. 215).

C-tests are based upon the same theory of closure or reduced redundancy as the cloze test. In C-tests, 
the second half of every second word is deleted and has to be restored by the reader (Klein-Braley, 1985).

Mousavi (2002) introduced Cl-test modifying the cloze procedure. It consists of four or five short texts in which half the letters of every other word are deleted, and the examinees receive credit for exact restorations. Since reading comprehension is a complex balance between recognizing printed symbols and internally interpreting the meaning behind the symbols, comprehension abilities vary among the individual learners. Reading comprehension also varies within the individual reader due to several factors. Educators can help their students strengthen their reading comprehension levels by knowing the factors that influence the readers' ability to understand what they have read. These factors are divided into two groups, namely internal factors (e.g., interest and motivation; strength as a reader; personality) and external factors (e.g., complexity of the piece, environmental influences, importance of the consequences).

The importance of the reason behind the reading task can also influence the students' ability to understand the material. Testing, classwork, or homework situations have greater consequences than reading for pleasure. Some students will react positively in testing and school situations, while others will be overwhelmed by the pressure to perform to a certain standard. Students suffering this anxiety may rush through the reading or not fully understand the instructions, resulting in confusion and poor comprehension of the material. Other students may force themselves to focus on the reading more closely, and be better able to comprehend it.

According to the explanation and clarification above, in order to examine the learners' personality type and reading strategies, the Myers-Briggs Type Indicator, Form M (MBTI-M) was used in this study. There are some strengths and weaknesses in the reliability and validity of the MBTI Form M according to Quenk (2000) as followings. The strengths are: (1) Its internal consistency is improved and also there exists test-retest reliabilities on all scales; (2) This form estimates the best fit type accurately; (3) There is a manual in which validity information accentuates research that studies the validity of whole types; and (4) There is a strong support by the data presented in the manual for type dynamics and the distinctiveness of the 16 types. The weaknesses are: (1) The time periods for the test-retest are short and the data yielded are based on small samples; (2) Larger samples would be suitable to best fit type with form M; (3) In order to do research on all16 types, one requires larger samples and a precise understanding of the MBTI theory; (4) Correlational studies of the four dichotomies are not as difficult as dynamics-oriented research techniques and results; and (5) The database of Form $M$ which is available for research is a limited database (p. 94).

\subsection{The Myers-Briggs Type Indicator}

Education is one of the various disciplines in which research has been done using the Myers-Briggs Type Indicator (MBTI). According to the Myers-Briggs Type Indicator (MBTI) instrument's publisher CCP, Inc. (Consulting Psychologists Press), the MBTI tools are available all over the world in 30 languages and it is claimed to be the most widely used personality inventory in the world (Consulting Psychology Press home page, http:// www.cpp.com/). An updated version of the MBTI instrument is Form M which is used for its construct validation to guarantee true score correlations with preference choices on each paired scale (Lucas, 2007). The MBTI Form M which is used for this study contains 93 items. This form is intended for 14-year-old people and upwards. The form is easy to complete, score and explain. It takes fifteen to twenty minutes to complete (Lucas, 2007). The form is divided into three parts. Part I consists of 26 questions in which the subject should select an answer from two choices that show mostly how he/she usually feels or acts. Part II contains 32 word pairs and the subject is asked to choose the word in each pair that fits him/her more. Part III includes 20 questions, where the respondent is asked to select the answer that tells how he/she usually feels or acts. Part IV includes 15 word pairs and the participant should select the word in each pair that appeals to him/her more.

Reliability and Validity of the MBTI - In this study, the researcher used the Persian version of the MBTI. The internal consistency of Persian translation was investigated by Bahri (2003). In order to do so, he used 
The impact of effective reading strategy instruction on EFL learners

Cronbach's Alpha coefficient of reliability, and he found results that "were quite satisfactory for three of four bipolar scales of the instrument, namely: $\mathrm{EI}=.83 \% ; \mathrm{TF}=.86 \% ; \mathrm{JP}=.84 \%$. The only alpha value which was below $.80 \%$ was the SI scale (.65\%). Bahri (2003) also investigated the construct validity of the MBTI. He ran a factor analysis by using Principal Component Analysis (PCA) and Principal Axis Factoring (PAF) techniques. He found some results which showed the extraction of four factors for the MBTI. "This evidence proves the MBTI developers claim that the test measures four bipolar scales of personality "(Bahri, 2003, p. 62).

\subsection{Personality Type and Its Implications to Education}

Personality type theory has various implications for training and education (Lucas, 2007). Personality type theory with its organized method helps to reach educational and training goals while being effective for the individual learners as well. Teachers can make better lesson plans and teaching methods when they have adequate knowledge about type. This way they can also choose activities which motivate learners according to their preferences. When personality types are associated with MBTI the information they yield helps learners to understand how to reach optimal learning, what they need to gain comprehension and also what a good presentation needs.

In order to define appropriate curriculum and instructional models and programs, knowledge of all type of dynamics and needs of personality types is considerably helpful. In most pedagogical situations, there are various mixed types and subdivision of groups according to their preference; what an instructor or a designer should do is to provide information in a way that all learners are involved. For example, an instructor should notice that learners are a combination of sensors and intuitive, and then he or she should make sure that a plan with organized items are presented for the sensors and a general picture of instructional programs' progression is provided for the intuitive. Furthermore, instructors should be conscious and concerned about learners' personality types without bias so that instructors will have better understanding of the methods the learners use. Personality type theory has various implications for training and education (Lucas, 2007). Teachers can make better lesson plans and teaching methods when they have adequate knowledge about type. This way they can also choose activities which motivate learners according to their preferences.

\subsection{Statement of the Problem}

The focus of this study was to examine the effect of explicit strategy instruction on reading comprehension achievement and also the relationship between the learners' personality types and their reading comprehension. Reduction of attention in reading comprehension skills affected a large number of learners while learning a foreign language. There are various factors that contribute to this reduction in reading comprehension. These factors include difficulties in learning reading skills, limited exposure to materials, and lack of effective instruction on techniques and strategies for approaching forms of higher level reading (Drucker, 2003; Mohr, 2004; Simmons, 1989; Snow, 2003).

This study contributed to the body of knowledge needed to address the issue of how explicit reading strategies instruction impacts the reading comprehension achievement of Iranian EFL elementary learners. At the same time, it should also be taken into consideration that just providing EFL learners with a list of reading strategies is not enough for them to become successful foreign language readers. Moreover, because everyone has his or her learning preference, in order to become motivated and selective strategy users, EFL learners need to self-regulate or self-monitor their reading strategy use (Anderson, 1991; Chamot, 2005). One factor which can take a lot of attention is the effect of personality type on learners' learning and achievements. As Myers, McCaulley, Quenk, and Hammer (1998) stated, when learners are forced into an environment that is out of their chosen preferred area, "it can discourage them by reinforcing activities that are less satisfying, less comfortable, and less motivating" (p. 28).

It is easy for teachers to choose one form of instructional method over another; however, if a teacher's 
chosen method of instruction or lack of motivation on the part of the learner is not compatible with the preference of a learner, then frustration or lack of motivation on the part of the learner is likely to result. If learners are withdrawing from the course material because of frustration, then success for the learner is nearly impossible (McGregor, 1997). Therefore, "An effective teacher knows how to support intrinsically motivated learners and seeks ways to provide extrinsic motivation to learners who need it" (Stronge, 2002, p. 18).

The MBTI provides information related to orientation of energy, processing of information, making decisions, and orientation to the outer world. For example, some teachers and learners are reserved while others are more outgoing. Likewise, there are learners and teachers who thrive in a structured learning environment while others prefer more freedom. MBTI explains these behaviors (McGregor, 1997). While research studies have examined the relationship between learning style and personality type, few have examined the relationship between reading strategies instruction and personality types of learners on their performance on reading comprehension test types. Thus, this research study examined this relationship to provide useful information for both teachers and learners.

\subsection{Significance of the study}

This study is significant primarily because it investigated not only what strategies EFL learners use when they read in English, but also provided insights on their actual use of those strategies to improve reading comprehension. Moreover, it helped teachers better understand different types of difficulties their learners encounter during the reading process so that they can address them accordingly. Apart from the aforementioned pedagogical implications, learners themselves also learned to benefit from the findings of this study by reflecting on their own reading experience. They learned more about the effectiveness of strategies and apply them to remove comprehension difficulties. Furthermore, examining EFL learners' strategy use raised learners' metacognitive awareness of some useful reading strategies they might not have come across before.

This study also aimed at what reading strategies to teach and how to teach them. It investigated whether teaching reading strategies in class influences EFL learners' performance on different reading comprehension test types. All learners do not use the same strategies while reading and there are many individual differences that could affect their use of these strategies. One of such differences is the personality type of the learners.

This study would be beneficial for both teachers and learners in increasing the awareness of how personality type may have an impact on the use of reading strategies. One of the outcomings of such awareness was the increase of motivation for learning on the part of learners. By understanding their personality type and their preferred reading strategies, learners could work on the development of those reading strategies that they felt less easy with. For teachers, such awareness could help to incorporate personality type into strategy training. Strategy training along with personality type awareness of the learners would help teachers to find which kind of strategies to teach and how to work with learners of different personality types.

\section{Methodology}

The aim of this study is to determine whether there is any significant differences between Iranian EFL learners' reading comprehension to whom reading strategies are instructed and those to whom the strategies are not instructed. This study also intends to solicit the participants' performance on different reading comprehension tests, such as cloze-test, cl-test. In addition, the participants' reading strategy preferences were investigated based on their personality types.

\subsection{Research questions}

The following research questions were formed concerning the effectiveness of explicit reading strategies instruction and their relationship with personality types of learners, and their performance in different tests of reading comprehension. 
$>\quad$ Is there any statistically significant difference between reading comprehension of those learners to whom reading strategies are instructed and that of those uninstructed?

$>\quad$ Is there any statistically significant relationship between the learners' reading comprehension and their personality types?

$>\quad$ What are the reading strategies preferred by EFL learners of different personality types?

$>\quad$ Is there any statistically significant relationship between strategic and nonstrategic readers' reading comprehension in different test types?

$>\quad$ What kinds of reading strategies do EFL learners mostly utilize?

\subsection{Hypotheses}

In order to investigate the aforementioned research questions empirically, the following four null hypotheses were formed:

$>\quad \mathbf{H}_{\mathbf{0}}$ 1. There is no statistically significant difference between reading comprehension of those learners to whom reading strategies are instructed and that of those uninstructed.

$>\mathbf{H}_{\mathbf{0}}$ 2. There is no statistically significant relationship between the learners' reading comprehension achievement and their personality types.

$>\quad \mathbf{H}_{\mathbf{0}}$ 3. There is no statistically significant difference in the reading strategies preferred by EFL learners of different personality types.

$>\mathbf{H}_{\mathbf{0}}$ 4. There is no statistically significant relationship between strategic and nonstrategic readers' reading comprehension in different test types.

$>\mathbf{H}_{\mathbf{0}}$ 5. There is no statistically significant difference between the types of reading strategies EFL learners mostly utilize.

\subsection{Participants}

A total of one hundred Iranian EFL adult learners at the elementary level within the age range of 15-30, studying at a private English language institute in Iran voluntarily participated in the first phase. The students had been learning English for about one and a half years. Persian is their native language and they had never been to an English-speaking country. The participants were informed of the study and the procedures of the research. To ensure the participants' homogeneity, the Key English Test (KET) was administered. Then, this total number of participants were reduced to a final number of 60 participants after homogenizing them based on their language scores. Finally, the participants were randomly assigned to two groups of 30 participants in each group, namely experimental and control group.

\subsection{Instrumentation}

In order to carry out this study, the following instruments were utilized: (a) KET was administered to a group of participants to make sure about their homogeneity. It consists of items assessing four language skills, and components; (b) a series of reading comprehension tests, including close-test, cl-test, c-test and z-test were administered to both experimental and control group to find out the participants' performance on various test types. (C) the two self-reported inventories, namely The Myers-Briggs Type Indicator and Form M (MBTI-M) were used to determine the personality type of the participants; (d) Mokhtari and Reichard's (2002) Reading Strategies Questionnaire (RSQ) was administered to assess participants' use of reading strategies.

\subsection{Reading Strategies Questionnaire}

There are different reading strategies questionnaires available. From among them, Mokhtari and Reichard's (2002) Reading Strategies Inventory was used because its theoretical basis seemed more comprehensive than others to the researcher. This questionnaire includes 38 items on a five-point Likert scale. It is divided into three groups each of which matches with one of the three reading strategy types indicated by Mokhtari \& Reichard (2002): (a) metacognitive strategies (items 1 to 13), (b) cognitive strategies (item 14to 30), and (c) support strategies (items 31to 38). Each item in the questionnaire is quantified with a score. "always" being associated with value of 1 , "often" 2, "sometimes" 3, "rarely" 4, and "never" 5. In this way each respondent receives a 
separate score for metacognitive, cognitive and support strategies. The interpretation of the scores was adopted from Mokhtari and Reichard (2002) which is based on Oxford's (1990) suggestion for language learning strategy usage. Three levels of strategy use are suggested, that is high (mean of 3.5 or higher), moderate (mean of 2.5 to 3.4), and low (2.4 or lower). The average for each category in the questionnaire shows which group of strategies (i.e., metacognitive, cognitive and support strategies) learners use most or least when reading. Saadinam (2004) translated and validated this questionnaire. In order to qualify the questionnaire with face, content, and construct validity, Saadinam reviewed literature and empirical research on reading strategies and considered the wording, format, and content of the questionnaire. She used Cronbach's alpha to establish the internal reliability of the questionnaire and obtained reliability coefficient of .77 which is of quite high value. She administered the questionnaire twice on the same group with an interval time of about two weeks. She did so because she wanted to compute the test-retest reliability and arrived at the Pearson Correlation of .80 .

\subsection{Materials}

One of the materials used in this study is the "American English File" book in elementary level. American English File offers updated content in every unit, additional grammar practice at the back of the book it provides opportunities to develop speaking and listening skills while including reading passages in each unit. American English File features contemporary topics and a strong focus on both accuracy and fluency. Its successful multi-skills syllabus integrates themes, grammar, functions, vocabulary, reading passages and specially pronunciation. The underlying philosophy of the course remains that language is best learned when it is used for meaningful communication. Written in American English, American English File reflects the fact that English is the major language of international communication and is not limited to any one country, region or culture. This book was used as the main textbook for the participants of the study. The collection of reading strategies taught were selected from Mokhtari and Reichard's (2002) inventory; namely, cognitive, metacognitive and support strategies. These strategies were instructed to the participants during 10 sessions of their 20 -session course (from session 4 to 13). Having taught each strategy, the researcher tried to help learners apply it to some new tasks, so that they could be able to use an inventory of reading strategies skillfully at the end of the course. Table 1 depicts the plan for each session.

\section{Table 1}

Mokhtari and Reichard's (2002) reading strategy

\begin{tabular}{|c|c|c|}
\hline Sessions & & Introducing three reading strategies in general \\
\hline 4 & \multirow{3}{*}{$\begin{array}{l}\text { Metacognitive } \\
\text { strategies }\end{array}$} & $\begin{array}{l}\text { Setting purpose for reading; Previewing text before reading; Checking how } \\
\text { text content fits purpose; Noting text characteristic }\end{array}$ \\
\hline 5 & & $\begin{array}{l}\text { Determining what to read; Using text features (e.g. tables); Using context } \\
\text { clues; Using typographical aids (e.g. italics) }\end{array}$ \\
\hline 6 & & $\begin{array}{l}\text { Predicting or guessing text meaning; Confirming predictions, and reviewing } \\
\text { the whole process }\end{array}$ \\
\hline 7 & \multirow{4}{*}{$\begin{array}{l}\text { Cognitive } \\
\text { Strategies }\end{array}$} & $\begin{array}{l}\text { Using prior knowledge; Reading aloud when text becomes hard; Reading } \\
\text { slowly and carefully; Trying to stay focused on reading }\end{array}$ \\
\hline 8 & & $\begin{array}{l}\text { Adjusting reading rate; Paying close attention to reading; Pausing and } \\
\text { thinking about reading; }\end{array}$ \\
\hline 9 & & $\begin{array}{l}\text { Visualizing information; Evaluating what is being read; Resolving conflicting } \\
\text { information; }\end{array}$ \\
\hline 10 & & $\begin{array}{l}\text { Rereading for better understanding; Guessing meaning of unknown words, } \\
\text { and reviewing the whole process }\end{array}$ \\
\hline 11 & \multirow{2}{*}{ Support strategies } & $\begin{array}{l}\text { Taking notes while reading; Underlining information in text; Using reference } \\
\text { materials }\end{array}$ \\
\hline 12 & & $\begin{array}{l}\text { Paraphrasing for better understanding; Asking oneself questions, and } \\
\text { reviewing the whole process }\end{array}$ \\
\hline
\end{tabular}




\section{Results}

\subsection{KET Results}

Before the instruction of reading strategies as a treatment, the two groups took KET test to be checked in terms of their language proficiency. The result of KET showed there was no significant difference in their language proficiency [experimental $\mathrm{M}=37.90, \mathrm{SD} 11.40$, control $\mathrm{M}=40.33, \mathrm{SD}=9.99$ with $\mathrm{t}(58)=-.879 p=.383$ ]

\subsection{Normality of the Distribution}

In order to check out whether normality of the distribution in this study, one-sample Kolmogorov-Smirnov (K-S) test with a set significance level of $p=.05$ was run on each of the tests. As shown in the table 2 , the results of $\mathrm{K}-\mathrm{S}$ test indicated the data is normally distributed.

Table 2

One-sample Kolmogorov-Smirnov Test for Pre and Post CL, Cloze, and MC Tests

\begin{tabular}{llcccccc}
\hline & & \multicolumn{3}{c}{ Kolmogorov-Smirnov $^{\mathrm{a}}$} & \multicolumn{3}{c}{ Shapiro-Wilk } \\
\cline { 3 - 8 } & & Statistic & $\mathrm{df}$ & Sig. & Statistic & df & Sig. \\
\hline \multirow{2}{*}{$\mathrm{CL}$} & Pretest & .152 & 60 & .421 & .952 & 60 & .392 \\
& Posttest & .172 & 60 & .541 & .908 & 60 & .531 \\
\multirow{2}{*}{ Cloze } & Pretest & .139 & 60 & .602 & .861 & 60 & .581 \\
& Posttest & .178 & 60 & .289 & .931 & 60 & .238 \\
\multirow{2}{*}{ MC } & Pretest & .109 & 60 & .076 & .953 & 60 & .068 \\
& Posttest & .177 & 60 & .309 & .930 & 60 & .241 \\
\hline
\end{tabular}

Note. ${ }^{a}$ Lilliefors Significance Correction

\subsection{Reliability}

In order to come up with an index of reliability, Cronbach alpha was calculated for the Myers-Briggs Type Indicator (MBTI) and the Reading Strategies Inventory. The obtained reliability index for the first questionnaire was .89. And, the obtained index of the reading strategy inventory was .91 . The results are shown in Tables 3 and 4.

Table 3

Reliability Statistics for MBTI

\begin{tabular}{ccc}
\hline Cronbach's Alpha & Cronbach's Alpha Based on Standardized Items & N of Items \\
\hline .896 & .895 & 93 \\
\hline
\end{tabular}

Table 4

Reliability Statistics for Reading Strategies Inventory

\begin{tabular}{ccc}
\hline Cronbach's Alpha & Cronbach's Alpha Based on Standardized Items & N of Items \\
\hline .916 & .913 & 38 \\
\hline
\end{tabular}

\subsection{Analysis of the Research Questions}

The first research question was: "Is there any statistically significant difference between reading comprehension of those learners to whom the strategies are instructed and that of those uninstructed?" 
Bozorgian, M., \& Aalaam, M.

The researcher went through a t-test analysis to compare the mean score of the experimental group with that of the control group in three reading comprehension test types. Table 5 indicates that the mean score in CL, Cloze, and MP reading comprehension tests are all higher than those of the control group

Table 5

Group Statistics for CL, Cloze, and MC Reading Comprehension Post-Tests

\begin{tabular}{llllll}
\hline & \multicolumn{1}{c}{ Groups } & $n$ & Mean & SD & SE \\
\hline CL post & experimental group & 30 & 17.00 & 1.554 & .284 \\
Cloze post & control group & 30 & 13.73 & 1.893 & .346 \\
& experimental group & 30 & 17.00 & 1.287 & .235 \\
MC post & control group & 30 & 14.87 & 2.583 & .472 \\
& experimental group & 30 & 17.00 & 1.145 & .209 \\
\hline
\end{tabular}

Levene's test for the equality of the variances showed that the normality of variance is not equal within the two groups. However, the independent t-test results show that there is a significant difference between the experimental and control in terms of their comprehension. The experimental group which received reading strategies instruction outperformed the control group in all three reading comprehension tests as shown in Table 6. Therefore, the first null hypothesis is rejected.

Table 6

Independent Samples Test for CL, Cloze, and MC Reading Comprehension Tests

\begin{tabular}{|c|c|c|c|c|c|c|c|c|}
\hline & & \multicolumn{2}{|c|}{$\begin{array}{c}\text { Levene's Test for Equality } \\
\text { of Variances }\end{array}$} & \multicolumn{5}{|c|}{ t-test for Equality of Means } \\
\hline & & $F$ & Sig. & $t$ & $d f$ & Sig. & $M D$ & $S E$ \\
\hline \multirow{2}{*}{ CL post } & $\begin{array}{l}\text { Equal variances } \\
\text { assumed }\end{array}$ & 3.971 & .051 & 7.307 & 58 & .000 & 3.267 & .447 \\
\hline & $\begin{array}{l}\text { Equal variances } \\
\text { not assumed }\end{array}$ & & & 7.307 & 55.880 & .000 & 3.267 & .447 \\
\hline \multirow{2}{*}{ Cloze post } & $\begin{array}{l}\text { Equal variances } \\
\text { assumed }\end{array}$ & 13.981 & .000 & 4.049 & 58 & .000 & 2.133 & .527 \\
\hline & $\begin{array}{l}\text { Equal variances } \\
\text { not assumed }\end{array}$ & & & 4.049 & 42.556 & .000 & 2.133 & .527 \\
\hline \multirow{2}{*}{ MC post } & $\begin{array}{l}\text { Equal variances } \\
\text { assumed }\end{array}$ & 17.422 & .000 & 4.524 & 58 & .000 & 2.133 & .472 \\
\hline & $\begin{array}{l}\text { Equal variances } \\
\text { not assumed }\end{array}$ & & & 4.524 & 42.377 & .000 & 2.133 & .472 \\
\hline
\end{tabular}

This finding of the current study is in line with many other pieces of research. Nikoopour, and Amini (2010) found out that the reading strategy training made a sound change in the learners' reading comprehension. In other words, instructing learners to use reading strategies while reading improves their comprehension, increases their reading speed, enhances their reading autonomy, and makes them more motivated to read independently and involves them in the reading process more.

Williams (2008) also noticed that the five learners' achievement increased according to their strategy scores. According to teacher observation and self-reports learners liked using strategies and learned three strategies throughout the year. There was diversity in the classroom and some of the learners needed individualized instruction and special help. Learners all learned how to use strategies at the same time.

The second research question was: "Is there any statistically significant difference between the learners' reading comprehension and their personality types?" 
The impact of effective reading strategy instruction on EFL learners

According to Table 7, the participants of different personality types did not show any significant differences in their reading comprehension pretests; that is, in all three types of reading comprehension tests, the difference is not significant.

Table 7

ANOVA Results for CL, Cloze, and MC Tests as Pretests

\begin{tabular}{|c|c|c|c|c|c|c|}
\hline & & $S S$ & $d f$ & Mean Square & $F$ & Sig. \\
\hline & Between Groups & 37.984 & 9 & 4.220 & 1.156 & .343 \\
\hline \multirow[t]{3}{*}{ CL pre } & Within Groups & 182.599 & 50 & 3.652 & & \\
\hline & Total & 220.583 & 59 & & & \\
\hline & Between Groups & 60.286 & 9 & 6.698 & .745 & .666 \\
\hline \multirow[t]{3}{*}{ Cloze pre } & Within Groups & 449.448 & 50 & 8.989 & & \\
\hline & Total & 509.733 & 59 & & & \\
\hline & Between Groups & 60.243 & 9 & 6.694 & 1.113 & .371 \\
\hline \multirow[t]{2}{*}{ MC pre } & Within Groups & 300.607 & 50 & 6.012 & & \\
\hline & Total & 360.850 & 59 & & & \\
\hline
\end{tabular}

The ANOVA results in Table 8 showed that the difference between the participants' personality types and their reading comprehension is significant in cl-test, and multiple-choice test; however, such difference in reading cloze test is not significant.

It is concluded that personality type functioned as a mediator variable and during the treatment, participants of various personality types showed statistically significant difference in their reading comprehension.

Table 8

ANOVA Results for CL, Cloze and MC Tests as Posttests

\begin{tabular}{lllllll}
\hline & & $S S$ & $d f$ & Mean Square & $F$ & Sig. \\
\hline \multirow{3}{*}{ CL post } & Between Groups & 91.811 & 9 & 10.201 & 2.107 & .046 \\
& Within Groups & 242.122 & 50 & 4.842 & & \\
\hline \multirow{5}{*}{ Cloze post } & Total & 333.933 & 59 & & & .639 \\
& Between Groups & 37.945 & 9 & 4.216 & .776 & \\
\hline \multirow{3}{*}{ MC post } & Within Groups & 271.788 & 50 & 5.436 & & .015 \\
& Total & 309.733 & 59 & & & \\
& Between Groups & 83.532 & 9 & 9.281 & & \\
\hline
\end{tabular}

As indicated in Table 10, the personality type of the learners did make a difference in their multiple-choice test and also cl-test, but in cloze test, participants with different personality types performed similarly.

A significant number of studies have delved into the possible relationship between EFL learners' personality types and different other variables that may have a prominent role in learners' success or failure. For example, Cohen (2008) in his study indicated that there appeared to be some correlation between specific dichotomies of MBTI, ILS, and LP. In another study among Japanese learners of the United States.

The results of this study seem to be more in line with the result of the research carried out by Nosratinia (2011) in which it was reported that there is a relationship between MBTI personality types and learning style preferences of Iranian EFL learners. Since each personality type we have dominates our actions, and decisions, in this regard, tests are not an exception in our performance. In the same vein, it can predict our performance and success in the test we take. Therefore, the kind of test we take and the personality type we have both can play a 
Bozorgian, M., \& Aalaam, M.

vital role in our success or failure in a reading test.

The issue has been investigated very deeply all over the world and a lot of pieces of research have been carried out on it. For an example, Tabataba'ian and Zabihi (2011) conducted the same study. They observed that while cognitive strategies were used quite often in reading different types of texts, socio-affective strategies were not used at all.

The third research question was: What are the reading strategies preferred by EFL learners of different personality types? Table 9 shows that participants with different personality types are significantly different in their choice of metacognitive reading comprehension strategies, but not significantly different in cognitive and support strategies. Using ANOVA shows whether there is such a difference statistically or not.

\section{Table 9}

ANOVA results for the preference of reading strategies

\begin{tabular}{lllllll}
\hline & & $S S$ & $d f$ & Mean Square & $F$ & Sig. \\
\hline \multirow{4}{*}{ Meta. strategies post } & Between Groups & 572.139 & 9 & 63.571 & 1.918 & .071 \\
& Within Groups & 1657.261 & 50 & 33.145 & & \\
& Total & 2229.400 & 59 & & & \\
Cog. strategies post & Between Groups & 1264.458 & 9 & 140.495 & 1.100 & .380 \\
& Within Groups & 6388.476 & 50 & 127.770 & & .767 \\
& Total & 7652.933 & 59 & & .629 & \\
Sup. strategies post & Between Groups & 124.044 & 9 & 13.783 & & \\
& Within Groups & 1096.140 & 50 & 21.923 & & \\
& Total & 1220.183 & 59 & & & \\
\hline
\end{tabular}

However, to show where the difference lies, there is a need to a Post Hoc multiple comparison in which all the possible combinations of personality types are compared to one another in terms of their choice of reading strategies. Due to the lack of space and practicality reason, the table showing this is shown in Appendix.

The fourth research question was: Is there any statistically significant relationship between strategic and nonstrategic readers' reading comprehension in different test types?

As shown in table 10, the correlation coefficients of CL and Cloze tests with reading strategies before the instruction are not only low but also insignificant. It shows that strategies instruction had a considerable effect on learners' $\mathrm{Cl}$ and Cloze tests' results. However, the statistical significance of the correlation coefficients reported in the output above shows that the learners did well on the post-tests of multiple choice reading comprehension test which is because of the impact of the strategies instruction. The significance levels reported for all three different strategies $(.026, .036, .019)$ are less than 0.05 which means that the hypothesis is rejected and there is a significant difference between strategic and nonstrategic learners' reading comprehension in different test types.

\section{Table 10}

Correlations between CL, Cloze, and MC Tests Results Before and After the Treatment

\begin{tabular}{|c|c|c|c|c|c|c|c|}
\hline & & \multicolumn{2}{|c|}{ Metacognitive } & \multicolumn{2}{|c|}{ Cognitive } & \multicolumn{2}{|c|}{ Support } \\
\hline & & pre & Post & Pre & post & Pre & post \\
\hline \multirow{2}{*}{ CL test } & Pearson Correlation & .185 & $.549 * *$ & .023 & $.623 * *$ & -.028 & $.629 * *$ \\
\hline & Sig. (2-tailed) & .157 & .000 & .860 & .000 & .832 & .000 \\
\hline \multirow{2}{*}{ Cloze test } & Pearson Correlation & .140 & $.299 *$ & .020 & $.402 * *$ & .070 & $.397 * *$ \\
\hline & Sig. (2-tailed) & .286 & .020 & .877 & .001 & .593 & .002 \\
\hline \multirow{2}{*}{ MC test } & Pearson Correlation & .198 & $.287 *$ & .042 & $.271 *$ & -.081 & $.303 *$ \\
\hline & Sig. (2-tailed) & .130 & .026 & .749 & .036 & .539 & .019 \\
\hline
\end{tabular}


The fifth question was: What kinds of reading strategies do EFL learners mostly utilize?

As the figure 1 depicts, Iranian EFL learners tend to use metacognitive strategies more than cognitive and support strategies. The second most frequent strategies are cognitive strategies, and obviously support strategies are used the least.

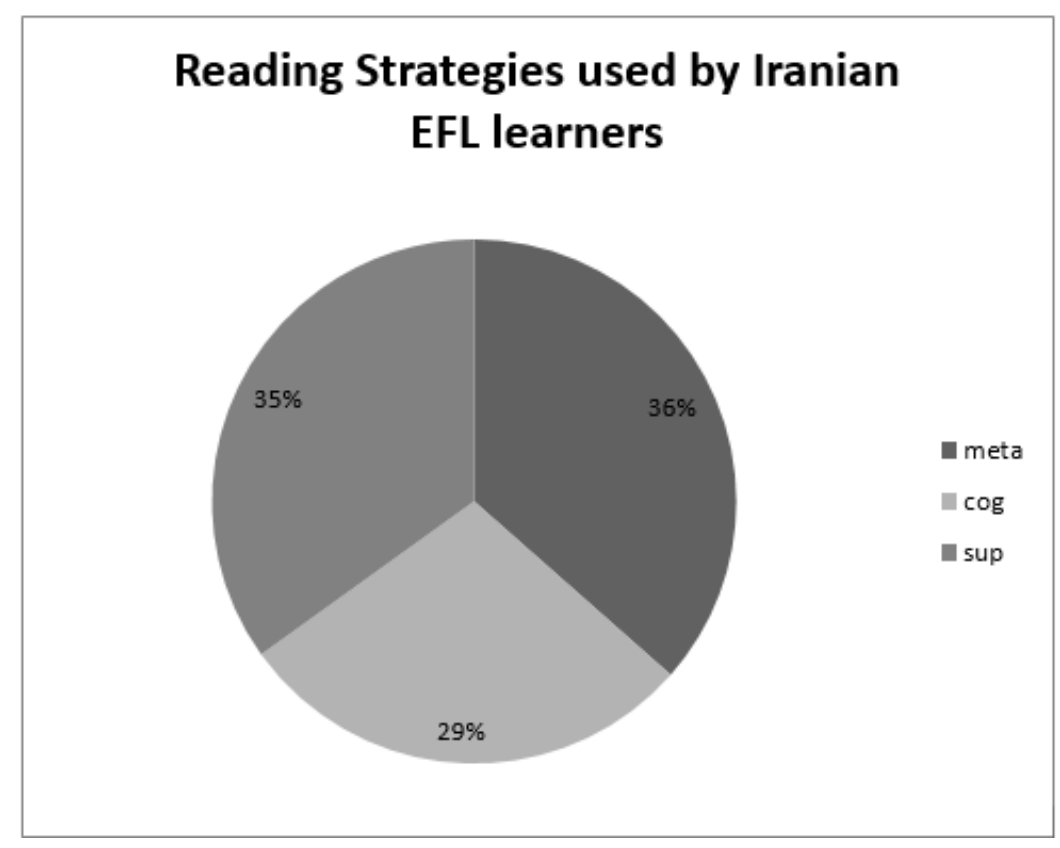

Figure 1. Reading strategies used by Iranian EFL learners

\section{Conclusion}

The study of reading strategies and personality types and the role reading strategies and personality types play in language learning enjoy a rich literature separately. Nevertheless, few studies have ever compared their possible relationships, the effect of test format, as well as the possible effect of training on learners' reading strategies. Hence, this led the researcher to explore the effect of training on learners' reading strategies as well as to explore the potential relationship between reading strategies, reading scores, and personality types among Iranian learners. Accordingly, 60 English learners were asked to fill in a questionnaire which gauged their reading strategies and their reading scores as well as their personality types.

The collected data were analyzed using SPSS version 24. For the first research question which was aimed at finding the difference between control and experimental learners in terms of their reading strategies, a set of Paired Samples T-tests was run. For the second research question, possible relationships between learners' reading score and their personality types were investigated and the means of the scores of pre and posttests of the different personality types were tabulated. In the third research question, reading strategies preferred by EFL learners of different personality types were observed. Regarding the fourth question, the results of comparison of the reading comprehension tests before and after treatment showed that reading strategies instruction helped learners to have a better reading comprehension. Finally, in the last research question it was revealed that Iranian EFL learners tend to use metacognitive strategies as their first choice and cognitive and support strategies as their second and third choices of strategies for their reading comprehension.

This study provides the EFL discourse community with some findings in the realm of foreign language learning. The results of the aforementioned analyses revealed that Iranian English learners at institutions are mostly aware of metacognitive strategies and less aware of cognitive and support strategies. Further, learners with different personality types were found to perform differently in various forms of reading comprehension tests. Metacognitive strategies were found to be used more frequently by Iranian EFL learners. 


\subsection{Pedagogical implications}

This study has several implications for the test developers, teachers and researchers. As the results indicated, personality type does have effects on learners' performance in reading comprehension tests. Therefore, it is believed that different test formats must be included in reading tests so that people who are better in one of these subscales are neither advantaged nor disadvantaged. Since fair assessment practice is the aim of testing and researchers all over the world are trying to develop fairer and more accurate tests, test developers must take care to integrate at least two types of tests in the reading comprehension tests they develop so that the tests assess performance of test takers more accurately and more fairly. The findings of this study help test developers and EFL teachers design reading comprehension tests that are free from sources of bias and treat test takers more equally. Teachers as test users must understand the qualities of the tests they use and their appropriateness in the context these tests are used. They must try to develop fairer tests which include all test formats. Therefore, it is important that the test format be known to the test takers; otherwise, they cannot perform well and the validity of the test will be under criticism.

\subsection{Suggestions for further research}

Obviously, no research effort is exhaustive in itself, and further research is needed to confirm, validate, and expand upon its results. Needless to say, the immediate study was just an endeavor to start a long, laborious way. Thus, several possible directions for future research have emerged from consideration of the study's procedure as following. First, the participants of the currents study were adult, elementary learners studying EFL at an institution setting; replications should be made using participants of diverse age groups, proficiency levels, and EFL locations. In addition, the number of participants in this study was limited to 60 learners; another research can be done on a larger population. Second, in other studies the age, the level of academic degree of teachers and the number of years they have experienced teaching can be considered as a control variable as well. Third, the significance of effects of strategies instruction on reading comprehension of the participants in the current study calls for the investigation of the impact on other language skills such as listening, writing and speaking. Further research should also consider carrying out other studies exploring the effect of personality types on learners' learning styles, thinking styles, cognitive styles, etc. and their performance on the different achievement tests. Finally, replication studies are advisable in order to permit greater confidence in the results.

\section{References}

Abbot, M. L. (2006). ESL reading strategies: Differences in Arabic and Mandarin speaker test performance. Language Learning, 56(4), 633-670. https://doi.org/10.1111/j.1467-9922.2006.00391.x

Alderson, J. C. (2000). Assessing reading. UK, Cambridge: Cambridge University Press. https://doi.org/10.1017/CBO9780511732935

Alfassi, M. (2004). Reading to learn: Effects of combined strategy instruction on high school learners. The Journal of Educational Research, 97(4), 171-184. https://doi.org/10.3200/JOER.97.4.171-185

Anderson, N. J. (1991). Individual differences in strategy use in second language reading and testing. The Modern Language Journal, 75(4), 460-472. https://doi.org/10.1111/j.1540-4781.1991.tb05384.x

Auerbach, E., Paxton, D. (1997). "It's not the English thing": Bringing reading research into the ESL classroom. TESOL Quarterly, 31(2), 237-261. https://doi.org/10.2307/3588046

Bahri, H. (2003). The relationship between personality type and learners' performance on the reading comprehension tests of the narrative and causeleffect texts (Unpublished master's thesis). Tarbiat Modares University, Tehran, Iran.

Barfarazi, F. (2008). The difference among Iranian EFL learner's reading strategy preferences based on their personality types (Unpublished master's thesis). Iran University of Science and Technology, Tehran, Iran.

Block, E. (1986). The comprehension strategies of second language readers. TESOL Quarterly, 20(3), 463-494. 
The impact of effective reading strategy instruction on EFL learners

https://doi.org/10.2307/3586295

Block, E., (1992). See how they read: Comprehension monitoring of L1 and L2 readers. TESOL Quarterly, 26(2), 319-343. https://doi.org/10.2307/3587008

Brown, H. D. (2001). Teaching by principles: An interactive approach to language pedagogy. New York, NY: Longman Publications.

Chamot, A. (2005). Language learning strategy instruction: Current issues and research. Annual Review of Applied Linguistics, 25, 112-130. https://doi.org/10.1017/S0267190505000061

Chastain, K. (1988). Developing second-language skills: Theory and practice ( $3^{\text {rd }}$ ed). San Diego, CA: Harcourt College Pub.

Cohen, J. J. (2008) Learning styles of Myers-Briggs type indicator (Unpublished master's thesis). Indiana State University, USA.

Drucker, M. J. (2003). What reading teachers should know about ESL learners. The Reading Teacher, 57(1), 22-29.

Garner, R., (1987). Metacognition and reading comprehension. Norwood, NJ: Ablex.

Gillet, J. W., Temple, C. A., Crawford, A. N., \& Cooney, B. (1990). Understanding reading problems: Assessment and instruction. Scott Foresman/Little, Brown Higher Education.

Gough, P., Ehri, L., and Treiman, R. (Eds.). (1992). Reading acquisition. Hillsdale, NJ: Erlbaum.

Grabe, W., (1991). Current developments in second language reading research. TESOL Quarterly, 25(3), 375-406. https://doi.org/10.2307/3586977

Iverson, K. J. (2005). The instruction of language learning strategies to low proficiency ESL learners. (Unpublished doctoral dissertation). Hamline University, Minnesota, USA.

Khoshsima, H., \& Pourjam, F. (2014). A comparative study on the effects of cloze tests and open-ended questions on reading comprehension of Iranian intermediate EFL learners. International Journal on Studies in English Language and Literature, 2(7), 17-27.

Klein-Braley, C. (1985). A cloze-up on the C-test: A study in the construct validation of authentic tests. Language Testing, 2(1), 76-104. https://doi.org/10.1177/026553228500200108

Lucas, D. J. (2007). Personality type (MBTI) relationship to performance and satisfaction in web-based instruction (WBI) (Unpublished doctoral dissertation). North California State University.

McGregor, P. (1997). Using Myers-Briggs type indicator to facilitate learner learning (Unpublished doctoral dissertation). University of Regina, Saskatchewan, Canada.

Mohr, K. (2004). English as an accelerated language: A call to action for reading teachers. 'The Reading Teacher, 58(1), 18-26. https://doi.org/10.1598/RT.58.1.2

Mokhtari, K., \& Reichard, C. (2002). Assissing students' metacognitive awareness of reading strategies. Journal of Educational Psychological, 94(2), 249-259. https://doi.org/10.1037/0022-0663.94.2.249

Mousavi, S.A. (2002). An encyclopedic dictionary of language testing $\left(3^{\text {rd }}\right.$ ed). Taipei, Taiwan: Tung Hua Book Company.

Munby, J. (1968). Read and think. Harlow: Longman.

Myers, I. B., McCaulley, M. H., Quenk, N. L., \& Hammer, A. L. (1998). Manual: A guide to the development and use of the Myers-Briggs Type Indicator. Palo Alto, CA: Consulting Psychologist Press.

Nikoopour, J., \& Amini Farsani, M. (2011). On the relationship between language learning strategies and personality types among Iranian EFL learners. Journal of English studies, 1(1), 81-101.

Nosratinia, M. (2011). The effect of personality type, learning styles, and strategies on Iranian M.A. EFL learners. Paper presented at the Conference of Teaching and Learning, Tehran, Iran.

Oxford, R. L. (1990). Language learning strategies: What every teacher should know. New York, NY: Newbury House.

Quenk, N. (2000). Essentials of Myers-Briggs type indicator assessment. New York, NY: John Wiley \& Sons.

Saadinam, R. (2004). The relationship between learner variables and reading strategy use of Iranian EFL learners (Unpublished master's thesis). Az-Zahra University, Tehran, Iran.

Sharp, A. (2004). Language learning and awareness of personality type in Chinese settings. Asian EFL Journal, $6(2), 1-13$. 
Bozorgian, M., \& Aalaam, M.

Simmons, S. M. (1989). PSRT- A reading comprehension strategy. Journal of Reading, 32(5), 419-427.

Singhal, M. (2001). The reading proficiency, reading strategies, metacognitive awareness and L2 readers. The Reading Matrix, 1(1). Retrieved from http://www/readingmatrix.com/articles/singhal/index.html

Snow, C. E. (2002). Reading for understanding: Toward an $R \& D$ program in reading comprehension. Santa Monica, CA: Rand.

Song, M.-J.. (1998). Teaching reading strategies in an ongoing EFL university reading classroom. Asian Journal of English Language Teaching, 8(1), 41-54.

Stronge, J. H. (2002). Qualities of effective teachers. Alexandria, VA: Association for Supervision Curriculum Development.

Tabataba'ian, M. S., \& Zabihi, R. (2011). Strategies used by four Iranian EFL learners in reading ESP and GPE texts: A think-aloud case study. World Journal of English Language, 1(1), 53-62.

Wei, Y. (2005). The relationship between phonological awareness and reading ability of Thai learners in English and Thai primary schools of Thailand (Unpublished doctoral dissertation). University of Maryland, College Park: MD.

Williams, P. M. (2008). The effects of teaching reading strategies on achievement and attitude (Unpublished masters' thesis). Southwest Minnesota State University. 


\section{Appendix}

Post Hoc multiple comparison of personality types and reading strategies

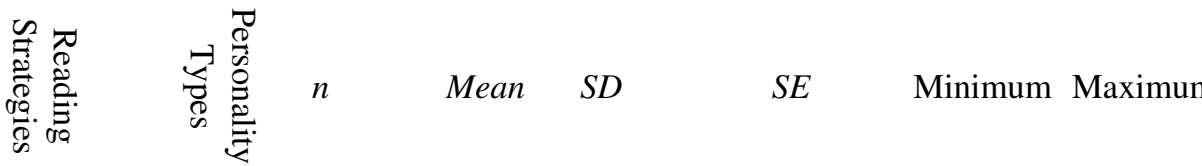

\begin{tabular}{|c|c|c|c|c|c|c|c|}
\hline \multirow{11}{*}{ 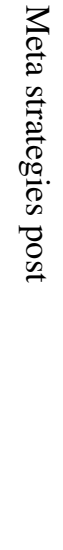 } & ISTJ & 11 & 33.36 & 5.853 & 1.765 & 23 & 40 \\
\hline & INFJ & 13 & 33.62 & 5.635 & 1.563 & 22 & 39 \\
\hline & ESTJ & 9 & 33.78 & 6.180 & 2.060 & 23 & 39 \\
\hline & ESTP & 4 & 29.25 & 6.702 & 3.351 & 23 & 36 \\
\hline & ESFJ & 6 & 28.00 & 4.899 & 2.000 & 22 & 34 \\
\hline & INFP & 2 & 27.00 & 2.828 & 2.000 & 25 & 29 \\
\hline & INTP & 3 & 25.67 & 5.132 & 2.963 & 20 & 30 \\
\hline & ISFP & 7 & 28.00 & 6.481 & 2.449 & 20 & 40 \\
\hline & ISTP & 3 & 32.67 & 5.508 & 3.180 & 29 & 39 \\
\hline & ISFJ & 2 & 24.00 & .000 & .000 & 24 & 24 \\
\hline & Total & 60 & 31.10 & 6.147 & .794 & 20 & 40 \\
\hline \multirow{11}{*}{ 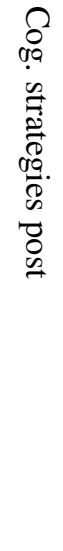 } & ISTJ & 11 & 48.64 & 9.708 & 2.927 & 26 & 57 \\
\hline & INFJ & 13 & 49.38 & 10.928 & 3.031 & 26 & 60 \\
\hline & ESTJ & 9 & 49.78 & 14.940 & 4.980 & 26 & 64 \\
\hline & ESTP & 4 & 43.25 & 15.174 & 7.587 & 26 & 56 \\
\hline & ESFJ & 6 & 37.50 & 11.292 & 4.610 & 30 & 60 \\
\hline & INFP & 2 & 47.00 & 5.657 & 4.000 & 43 & 51 \\
\hline & INTP & 3 & 39.33 & 16.166 & 9.333 & 30 & 58 \\
\hline & ISFP & 7 & 44.57 & 6.729 & 2.543 & 40 & 57 \\
\hline & ISTP & 3 & 50.33 & 6.028 & 3.480 & 44 & 56 \\
\hline & ISFJ & 2 & 35.00 & .000 & .000 & 35 & 35 \\
\hline & Total & 60 & 46.13 & 11.389 & 1.470 & 26 & 64 \\
\hline \multirow{11}{*}{ 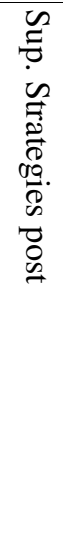 } & ISTJ & 11 & 20.27 & 3.580 & 1.079 & 15 & 26 \\
\hline & INFJ & 13 & 20.38 & 5.316 & 1.474 & 13 & 28 \\
\hline & ESTJ & 9 & 20.33 & 6.021 & 2.007 & 13 & 27 \\
\hline & ESTP & 4 & 19.50 & 6.608 & 3.304 & 12 & 26 \\
\hline & ESFJ & 6 & 18.50 & 4.278 & 1.746 & 16 & 27 \\
\hline & INFP & 2 & 16.00 & 1.414 & 1.000 & 15 & 17 \\
\hline & INTP & 3 & 19.33 & 2.309 & 1.333 & 18 & 22 \\
\hline & ISFP & 7 & 17.57 & 3.309 & 1.251 & 16 & 25 \\
\hline & ISTP & 3 & 18.00 & 4.359 & 2.517 & 15 & 23 \\
\hline & ISFJ & 2 & 15.00 & .000 & .000 & 15 & 15 \\
\hline & Total & 60 & 19.28 & 4.548 & .587 & 12 & 28 \\
\hline
\end{tabular}


Bozorgian, M., \& Aalaam, M. 